\title{
Modelling of Alpha and Beta for Rain Rate Prediction for Radio Propagation Systems
}

\author{
Y. K. Sanusi, O. Oyeleke, A. O. J. Abiodun and G. A. Alagbe
}

\begin{abstract}
The effect of rain in the design of satellite and terrestrial microwave radio links is of interest to Engineers and Scientists. It is good to have a reliable design that guarantees high level of accuracy of the rain rate distribution from the lowest rain rate value to the highest. The present work proposes a model that expresses rain rate as a function of alpha and beta obtained at $0.01 \%$ of time. When tested, the results obtained with the measurement perform well for the stations considered at a rain rated between $5 \mathrm{~mm} / \mathrm{h}$ to $200 \mathrm{~mm} / \mathrm{h}$. Thus, $\alpha$ and $\beta$, the empirical models that were obtained through them could be a useful tool for the radio design engineers for high rain rate areas.
\end{abstract}

Index Terms — Radio propagation, Rain Rate, Model, Attenuation, cumulative Distribution.

\section{INTRODUCTION}

Attenuation due to rainfall plays significant roles in the design of earth satellite radio link at frequencies above $10 \mathrm{GHz}$ [1]. The increasing demand for these frequencies for telecommunication and broadcasting satellite has arouse interest in the study of radio wave attention due to rainfall on earth-satellite radio paths. Most of the attenuation studies on earth-satellite path have been carried out in the temperature regions of the world [2].

The precipitation characteristics in the tropics differ appreciably from those of the temperate regions in that empirical relationship obtained in the temperate region may not be very suitable for the system design in the tropical region. Rain attenuation can be obtained directly from rain drop size distribution [2]. It is well known that rain rates and the consequent high rain attenuation in the tropics is arguably the greatest constraint to the usability of $\mathrm{Ku}$ and $\mathrm{Ka}$ bands in the tropics [3]. However, in this work, rainfall intensity $\mathrm{R}_{0.01}$ $(\mathrm{mm} / \mathrm{h})$ exceeded for $0.01 \%$ of the time in different in different locations are studied and a model that expresses rain rate as a function of alpha and beta was proposed. ' $\alpha$ ' and ' $\beta$ 'parameters at that percentage of time are very important tools for radio wave attenuation predictions both on line-ofsight and Earth-space links.

\section{A. Rain Distribution Models}

[4] has proposed a model of rain distribution of the from:

Published on July 17, 2020.

Y. K. Sanusi, Ladoke Akintola University of Technology, Nigeria.

(corresponding e-mail: sanusiyk33@gmail.com)

O. Oyeleke, The Federal Polytechnic Offa, Nigeria.

DOI: http://dx.doi.org/10.24018/ejece.2020.4.4.223

$$
\mathrm{P}(\mathrm{R} \geq r)=\frac{a e^{-u r}}{r^{b}}=r \geq 2 m m / h
$$

Where $\mathrm{P}(\mathrm{R}>\mathrm{r})$ is the probability that a rain rate, $\mathrm{R}$ exceeds a certain threshold $r$, "a" and " $b$ " are parameter depending on rain intensity for which one variant is given by:

$$
\begin{aligned}
& a=10^{-4} R^{b} 0.001 \exp \left(U^{R 0.01}\right) \\
& \mathrm{b}=8.22 \mathrm{R}^{-0.584}{ }_{0.01}
\end{aligned}
$$

[5] proposed a prediction procedure of rainfall rate cumulative distribution which is probability law leading to a more accurate prediction of rainfall rate cumulative distribution for all climates. The rain rate data obtained using a fast rain gauge with an integration time of 10 seconds at IleIfe in Nigeria from September 1979 to December 1981 were used to study the dependence of rain statistics on integration time. The power law between the rain of different integration given by [2] was:

$$
\mathrm{R}_{\mathrm{t}}=\mathrm{aR}_{\mathrm{t}}^{\mathrm{b}}
$$

Where $\mathrm{R}$ is the rain rate $\mathrm{T}$ is the integration time, at which the rain rate is available, "a" and " $\mathrm{b}$ " are parameters for location. [2] obtained the lognormal model using method of moment regression over a range of $0.25 \mathrm{~mm} / \mathrm{h}$ to $150 \mathrm{~mm} / \mathrm{h}$.

The model is given by:

$$
\mathrm{N}_{(\mathrm{D})}=\frac{N_{T}}{\sigma D \sqrt{2 \Pi}} \exp \frac{\left[-1 / 2(\ln D-\mu)^{2}\right]}{\sigma}
$$

With Ile-Ife data, [2] obtained the following relation

$$
\begin{aligned}
& \mathrm{N}_{\mathrm{T}}=108 \mathrm{R}^{0.363} \\
& \mu=-0.195+0.199 \ln \mathrm{R} \\
& \sigma=0.137+0.013 \ln \mathrm{R}
\end{aligned}
$$

[3] - [5] carried out an inter-comparison of raindrop size distribution models presented by [8.9.10,11].

A. O. J. Abiodun, Lead University, Nigeria.

G. A. Alagbe, Ladoke Akintola University of Technology, Nigeria. 
[5] - [7] used the raindrop spectra data obtained at Ile-Ife three years to investigate the dependence of drop size distribution on rain type and location. The conclusion was that the negative exponential model is adequate for drizzle whereas, the lognormal provides a better fit for the widespread shower and thunderstorm rains.

\section{METHODS}

In view of the above, rain data were collected at the university of Ilorin over a period of two years $1^{\text {st }}$ January 2004 to $31^{\text {st }}$ December 2005 in the physics department metrological station and cumulative distribution of rain rate computed.

\section{A. Rain Rate Model}

From the graph displayed by rain rate computed against the percentage of time, the equation 9 , below was obtained.

$$
\operatorname{Rr}=\frac{\alpha}{(\% t) \beta}
$$

Where $(\% \mathrm{t})$ can be replaced using $\Gamma$ which gives $\mathrm{R}_{\mathrm{r}}=$ $\frac{\alpha}{\Gamma^{\beta}}$ [6], for each station, $\alpha$ and $\beta$ were obtained as shown in Table 1.

TABLE 1: THE VARIABILITY OF PARAMETERS ‘ $\alpha$ ' AND ‘ $\beta$ ’ With

\begin{tabular}{lccc}
\multicolumn{4}{c}{ GEOGRAPHICAL LOCATIONS } \\
\hline Location & $\alpha$ & $\beta$ & No of Years \\
\hline Brazilia & 5.255 & -0.365 & 1 \\
Nairobi & 6.3396 & -0.435 & 1 \\
Daressalem & 8.1138 & -0.406 & 1 \\
Ile -Ife & 13.4246 & -0.3738 & 1 \\
Ilorin & 16.626 & -0.3691 & 2 \\
\hline
\end{tabular}

\section{Cumulative Distribution of Rainfall}

The cumulative distribution of the rainfall intensity was evaluated using the following procedure:

Yearly percentage of time expressed as:

$$
(\% \mathrm{t})=\frac{t}{T} \times 100
$$

Where $t$ is the total time during which rain rate $\mathrm{R}$ is exec ceded and $\mathrm{T}$ is the overall period of interest taken to be one year in evaluating the yearly cumulative distribution for a non-leap year the percentage of time for the first minute will be:

$$
\% \mathrm{t}=\frac{t}{T} \times 100=\left(\frac{1}{365 \times 24 \times 60}\right) \times 100=1.9 \times 10^{4} / \mathrm{hr}
$$

For monthly cumulative distribution;

$$
\% \mathrm{t}=\frac{t}{T} \times 100=\left(\frac{t}{N_{\text {day } \sin \text { themont }} \times 24 \times 60}\right) \times 100
$$

\section{RESULTS AND DISCUSSION}

A. Behaviour of alpha and beta at $R_{0.01}(\mathrm{~mm} / \mathrm{h})$

Table 2 below shows the values of parameters ' $\alpha$ ' and ' $\beta$ ' computed by the use of regression programme. The rain rate obtained for the different locations at $\mathrm{R}_{0.01}$ are provided.

TABLE 2: THE VARIABILITY OF PARAMETERS ' $\alpha$ ' AND ‘ $\beta$ ' With RAIN

\begin{tabular}{l|c|c|c}
\multicolumn{4}{c}{ RATE AT DIFFERENT LOCATIONS } \\
\hline Location & \multicolumn{2}{c}{ Values of Parameters } & $\mathrm{R}_{0.01}(\mathrm{~mm} / \mathrm{h})$ \\
\hline & $' \alpha ' \beta '$ & \\
\hline Brazilia & 5.255 & -0.365 & 50 \\
Nairobi & 6.359 & -0.435 & 58 \\
Daresslam & 8.110 & -0.406 & 72 \\
Ile-Ife & 13.446 & -.03738 & 80 \\
Ilorin & 16.625 & -0.3691 & 90 \\
& & &
\end{tabular}

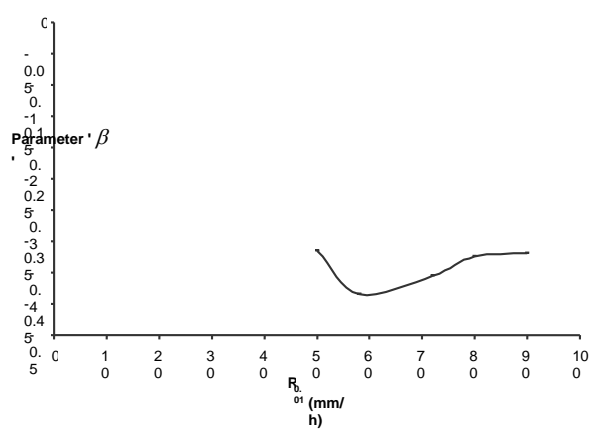

Fig 1 . The graph of parameter $\beta$ against rainfall intensity at $0.01 \%$

In Fig. 1, the parameters ' $\beta$ ' plotted against the values of rainfall intensity during the $0.01 \%$ of the time for each location in table 2 . The corresponding point can be fitted by the equation 11:

$$
\beta_{\mathrm{p}}=0.0025 \mathrm{R}_{0.01}-0.5826
$$

For all the stations considered, there is a good agreement between the values obtained from the predicted equations and the values obtained from the measurement. $\beta_{\mathrm{m}}$ is measurement value and $\beta_{\mathrm{p}}$ is predicted value of $\beta$.

TABLE 3: The Values $\beta$ Of Both Predicted And Measurement WITH RAIN RATE

\begin{tabular}{llll}
\hline Parameters & & & \\
\hline $\mathrm{R}_{0.01}(\mathrm{~mm} / \mathrm{h})$ & $\beta_{\mathrm{m}}$ & $\beta_{\mathrm{p}}$ & \% error \\
\hline 90 & -0.3691 & -0.3576 & 3.1 \\
80 & -0.3728 & -0.3826 & -2.4 \\
72 & -0.4060 & -0.4026 & 0.8 \\
58 & -0.4350 & -0.4376 & -0.6 \\
50 & -0.40650 & -0.4876 & 0.2 \\
\hline
\end{tabular}




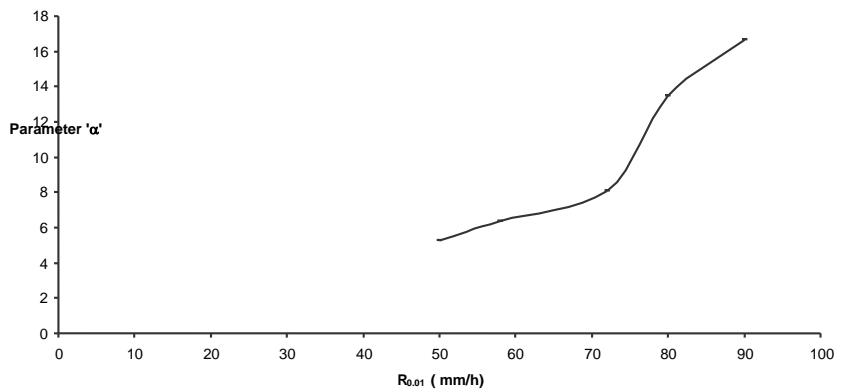

Fig 2. The graph of parameter ' $\alpha$ ' against rainfall intensity at $0.01 \%$

Parameters ' $\alpha$ ' plotted against corresponding $\mathrm{R}_{0.01}(\mathrm{~mm} / \mathrm{h})$ has resulted into a linear equation and the empirical equation is now written as equation (12):

$$
\alpha_{p}=0.288 R_{0.01}-10.199
$$

Equation 12 was then used to generate predicted values ' $\alpha$ ' results into table 4

TABLE 4: The VAlues $\boldsymbol{\alpha}$ Of Both Predicted And Measurement WITH RAIN RATE

\begin{tabular}{llll}
\multicolumn{4}{c}{ WITH RAIN RATE } \\
\hline Parameters & \multicolumn{3}{c}{} \\
\hline $\mathbf{R}_{\mathbf{0 . 0 1}}(\mathbf{m m} / \mathbf{h})$ & $\boldsymbol{\alpha}_{\mathbf{m}}$ & $\boldsymbol{\alpha}_{\mathbf{p}}$ & \% error \\
\hline 90 & 16.625 & 15.721 & -5.5 \\
80 & 13.446 & 12.841 & -4.5 \\
72 & 8.110 & 10.537 & 30.0 \\
58 & 6.359 & 6.0505 & 2.3 \\
52 & 5.255 & 4.201 & 20.1
\end{tabular}

$\alpha_{\mathrm{m}}$ is measurement value and $\alpha_{\mathrm{p}}$ is predicted value of $\alpha$.

Tables 3 and 4 revealed the consistency of the empirical equation obtained from the graphs (Fig. 1 and 2) of Parameter ' $\beta$ ' versus $\mathrm{R}_{0.01}(\mathrm{~mm} / \mathrm{h})$ and Parameter ' $\alpha$ ' versus $\mathrm{R}_{0.01}$ $(\mathrm{mm} / \mathrm{h})$.

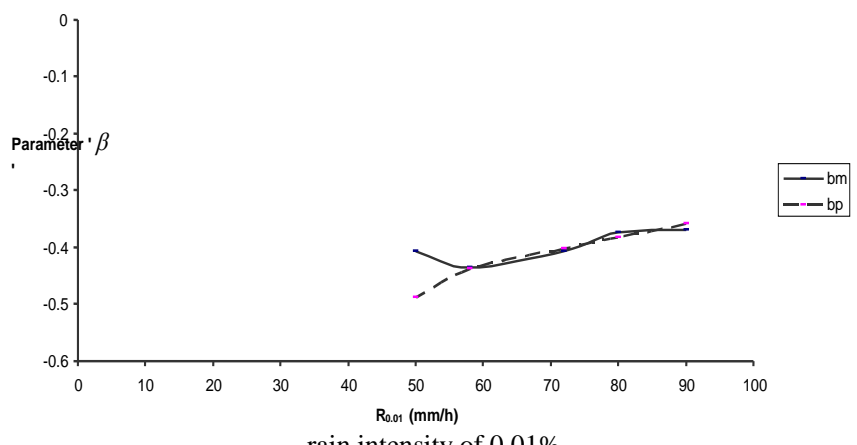

Fig 3. Comparison between parameter ' $\beta$ ' obtained by measurement and prediction

Figures 3 and 4 are graphs that compare the values of parameters ' $\alpha$ ' and ' $\beta$ ' obtained by measurement and the ones obtained by prediction. Since these parameters are very important in the prediction of rain-rate from the previous model [6], $\mathrm{R}_{\mathrm{p}}=\alpha \Gamma^{-\beta}$.

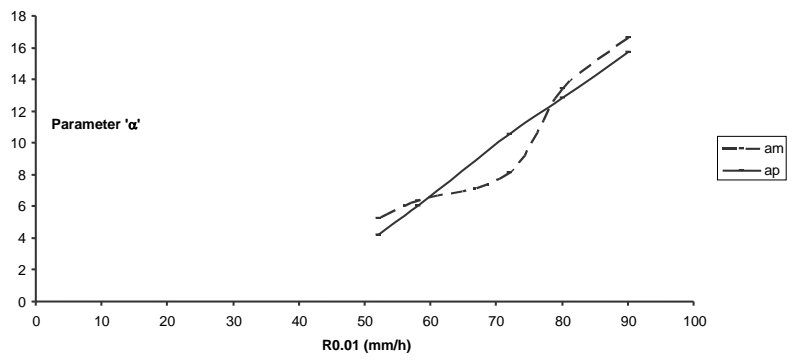

rain intensity of $0.01 \%$

Fig 4. Comparison between parameter ' $\alpha$ ' obtained by measurement and prediction.

Substituting these values of ' $\alpha$ ' and ' $\beta$ ' and varying the percentage of time, the following tables were obtained using $\alpha_{\mathrm{p}}=0.288 \mathrm{R}_{0.01}-10.199$ and $\beta_{\mathrm{p}}=0.0025 \mathrm{R}_{0.01}-0.5826$ for the stations considered.

Comparing Rain-rate obtained by the use of predicted equation for ' $\alpha$ ' and ' $\beta$ '

TABLE 6 (A) ILORIN: R0.01 = 90MM/H, $\alpha=15.72, \beta=-0.3691$

\begin{tabular}{llll}
\hline \% of time & $\mathbf{R}_{\mathbf{m}}(\mathbf{m m} / \mathbf{h})$ & $\mathbf{R}_{\mathbf{p}}(\mathbf{m m} / \mathbf{h})$ & \% error \\
\hline 0.001 & 198 & 201.3 & -1.7 \\
0.003 & 152 & 134.2 & -11.7 \\
0.01 & 90 & 86.0 & -4.4 \\
0.03 & 60 & 57.4 & -4.3 \\
0.1 & 45 & 36.8 & 18.2 \\
0.3 & 23 & 24.5 & 6.5 \\
\hline
\end{tabular}

TABLE 6 (B): ILE-IFE: R0.01= $80 \mathrm{MM} / \mathrm{H}, \alpha=12.841, \beta=-0.3826$

\begin{tabular}{llll}
\hline \% of time & $\mathbf{R}_{\mathbf{m}}(\mathbf{m m} / \mathbf{h})$ & $\mathbf{R}_{\mathbf{p}} \mathbf{~ m m} / \mathbf{h}$ & \% error \\
\hline 0.001 & 140 & 180.5 & 29 \\
0.003 & 125 & 118.5 & -5.2 \\
0.01 & 80 & 74.8 & -6.5 \\
0.03 & 65 & 49.1 & -24.5 \\
0.1 & 38 & 31.9 & -16.8 \\
0.3 & 15 & 20.4 & 36 \\
\hline
\end{tabular}

TABLE 6 (C): BRAZILIA R0.01= 50MM/H, $\alpha=4.201, \beta=-0.4876$

\begin{tabular}{llll}
\hline \% of time & $\mathbf{R}_{\mathbf{m}}(\mathbf{m m} / \mathbf{h})$ & $\mathbf{R}_{\mathbf{p}}(\mathbf{m m} / \mathbf{h})$ & \% error \\
\hline 0.001 & 95 & 121.9 & 28.3 \\
0.003 & 64 & 71.4 & -116 \\
0.01 & 50 & 39.7 & 20.6 \\
0.03 & 32 & 23.2 & -27.5 \\
0.1 & 16 & 12 & 25.0 \\
0.3 & 06 & 7.6 & 26.7 \\
\hline
\end{tabular}

TABLE 6 (D): NAIROBI R0.01 = 58MM/H, $\alpha=6.3391, \beta=-0.435$

\begin{tabular}{llll}
\hline \% of time & $\mathrm{R}_{\mathrm{m}}(\mathrm{mm} / \mathrm{h})$ & $\mathrm{R}_{\mathrm{p}}(\mathrm{mm} / \mathrm{h})$ & \% error \\
\hline & & & \\
\hline 0.001 & 95 & 127.9 & 34.6 \\
0.003 & 76 & 79.4 & 4.3 \\
0.01 & 58 & 47 & 19 \\
0.03 & 40 & 29 & -27.5 \\
0.1 & 20 & 12 & 15 \\
0.3 & 08 & 10.8 & 26.7 \\
\hline
\end{tabular}


TABLE 6 (E): DARESSLAM, R0.01 = 72MM $/ \mathrm{H}, \alpha=10.537, \beta=0.350$

\begin{tabular}{llll}
\hline \% of time & $\mathrm{R}_{\mathrm{m}}(\mathrm{mm} / \mathrm{h})$ & $\mathrm{R}_{\mathrm{p}}(\mathrm{mm} / \mathrm{h})$ & \% error \\
\hline 0.001 & 96 & 118.2 & -23.1 \\
0.003 & 86 & 80.5 & -6.4 \\
0.01 & 72 & 52.5 & -27 \\
0.03 & 46 & 36 & -21.7 \\
0.1 & 19 & 23 & 21.1 \\
0.3 & 13 & 16 & 23.5 \\
\hline
\end{tabular}

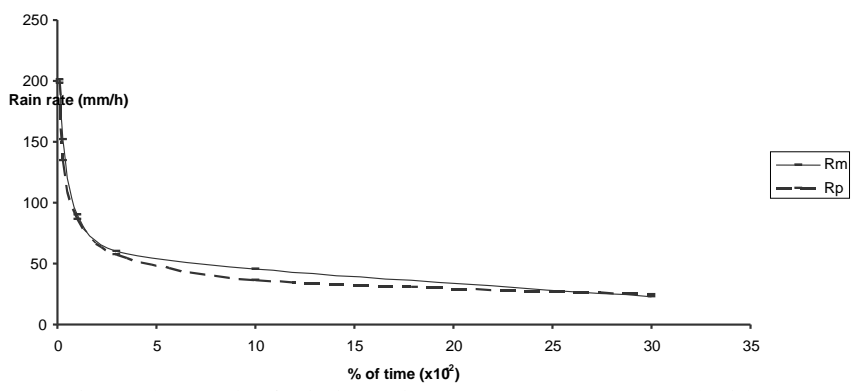

Fig 5. The graph of rain intensity measurement compared with the prediction from Predicted equations for $\alpha$ and $\beta$ at R0.01 for Ilorin.

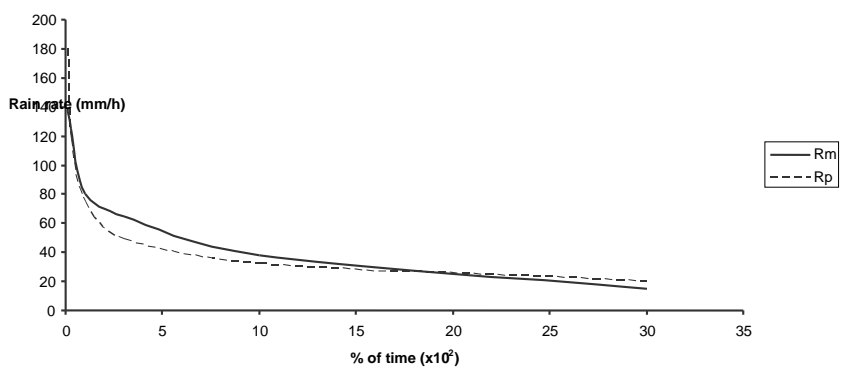

Fig 6. The graph of rain intensity measurement compared with the prediction from Predicted equations for $\alpha$ and $\beta$ at R0.01 for Ile-Ife.

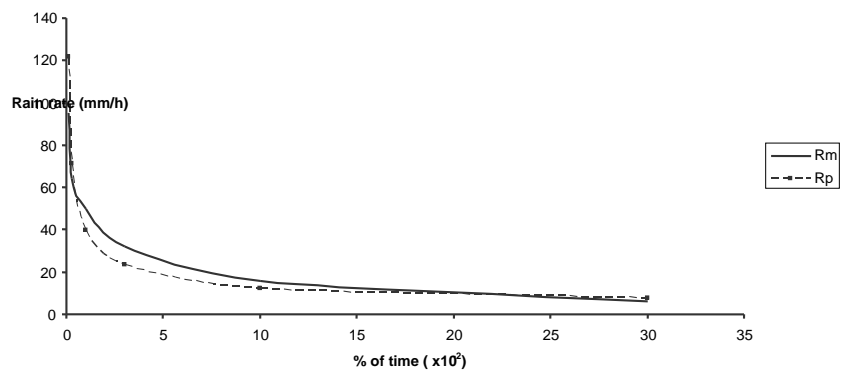

Fig 7. The graph of rain intensity measurement compared with the prediction from Predicted equations for $\alpha$ and $\beta$ at R0.01 for Brazilia.

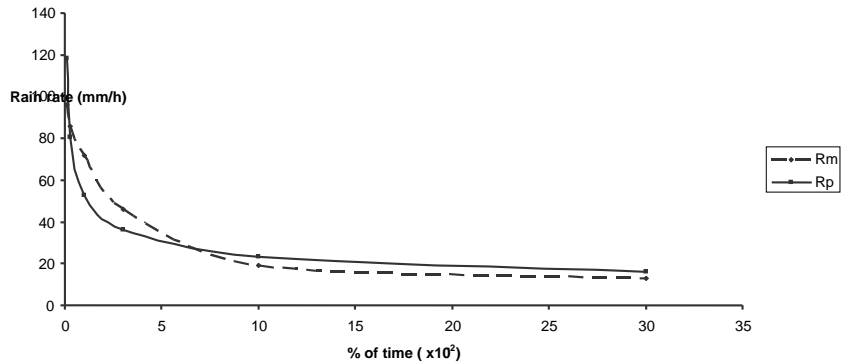

Fig 9. The graph of rain intensity measurement compared with the prediction from Predicted equations for $\alpha$ and $\beta$ at R0.01 for Dar -es salam.

Fig. 5-9 are graphs that reveal the performance of the prediction of parameters ' $\alpha$ ' and ' $\beta$ ' at $\mathrm{R}_{0.01}$ for different locations. The figures highlight that the prediction is in close agreement with the measurement when parameters are used.

\section{CONCLUSION}

The initially proposed power law model of the form $\alpha \Gamma^{-\beta}$ gave a very good prediction for the rain-rate up to $200 \mathrm{~mm} / \mathrm{h}$. The new parameters later proposed at rain-rate $0.01 \%$ of time, gives a very good representation of the parameters for the stations considered. The linear relationship that exist between ' $\alpha$ ' and ' $\beta$ ' at the rain rate $0.01 \%$ of time makes the prediction for cumulative rain rate distribution easy and gives a very good fit for the medium and high rain rate locations, especially in the tropical regions.

The linear models for ' $\alpha$ ' and ' $\beta$ ' , $\alpha_{\mathrm{p}}=\mathrm{M}_{\alpha} \mathrm{R}_{0.01}-\mathrm{C}_{\alpha}$ and $\beta_{\mathrm{p}}=M_{\beta} \mathrm{R}_{0.01}-C_{\beta}$

Where $M_{\alpha}$ and $M_{\beta}$ are the slopes of the graph plotted for ' $\alpha$ ' versus $\mathrm{R}_{0.01}$ and ' $\beta$ versus $\mathrm{R}_{0.01}$ respectively $C_{\alpha}$ and $C_{\beta}$ are the intercepts obtained on their vertical axis respectively.

For all the stations considered in this work, the consistency test conducted holds well for the measurement of about $5 \mathrm{~mm} / \mathrm{h}$ to about $200 \mathrm{~mm} / \mathrm{h}$. In addition to the behaviour of the parameters, $\alpha$ and $\beta$, the empirical models that were obtained through them could be a useful tool for the radio design engineers for high rain rate areas.

\section{REFERENCES}

[1] Adimula, I.A., Oyinloye, J.O and Owolabi, I.E. (1991): Rain intensity measurement in Nigeria for microwaves application. Proc $3^{\text {rd }}$ Biregional African - Latin American conference on radio propagation and spectrum management foz do Iguah, Brazil PP171-179

[2] Ajayi, G.O and Olsen, R.L (1985): Modelling of a tropical raindrop size distribution for microwave and millimetre wave applications. Radio Sci., Vol. 20, No 2, P.193-2002

[3] Ajayi, G.O and Ofoche, E.B.C (1984): Some tropical rainfall rate characteristics at Ile- Ife for microwave and millimeter wave application. Journal of climate and applied meteorology volume $23 \mathrm{No}$ 4 pp 563.

[4] Abayomi I Y, and Nor HHK (2014) Rain Attenuation Prediction Model for Lagos at Millimeter Wave Bands, J. Atmos. Oceanic Technol. (2014) 31 (3): 639-646 
[5] Adegoke AS and Onasanya MA (2008) Effect of Propagation delay on signal Transmission. Pacific Journal of Science and Technology (USA) Vol 9 (1) pg 13-19

[6] Moupfouma F and Martin. L (1995) Modeling of rainfall rate cumulative distribution for the design of satellite and terrestrial comm. System" Int J. Satelite Comm volume 13. PP 105.

[7] Maitran A (2004) Rain Attenuation Modelling from Measurements of Rain Drop Size Distribution in the India Region. IEEE Antena and Wireless Propagation Letter Vol 3

[8] Moupfouma, F and Martin (1993) Point rainfall rate cumulative distribution function valid at various locations in the world, electronics letters, vol 29 No 7 PP 1503-1504.

[9] Oyeleke, O. (2010): (Unpublished) Rain-rate model for Tropical Regions for Radio Propagation Applications. An M.Sc thesis submitted to the department of physics, University of Ilorin, Ilorin Nigeria.

[10] Moupfouma F (1987) More about rainfall rate and their prediction for radio systems Engineering” IEE Proc. Volume 134 Pt. H. No 6 PP 527530.

[11] Massambami O and Rodriquez C.A.M (1991) Intercomparison of models for rain attemation prediction as inferred from DSD Measurements in the tropics. Pro1 $3^{\text {rd }}$, Biregional African - Latin American Conference and Radio propagation and spectrum management Fo3, do Ingueche, Brazil PP 161 - 170. 